\title{
Laurence Tricoche-Rauline, Identité(s) libertine(s). L'écriture personnelle ou la création de soi
}

\section{Laura Rescia}

\section{(2) OpenEdition}

1 Journals

\section{Edizione digitale}

URL: http://journals.openedition.org/studifrancesi/6614

DOI: 10.4000/studifrancesi.6614

ISSN: 2421-5856

\section{Editore}

Rosenberg \& Sellier

\section{Edizione cartacea}

Data di pubblicazione: 1 septembre 2010

Paginazione: 359

ISSN: 0039-2944

\section{Notizia bibliografica digitale}

Laura Rescia, «Laurence Tricoche-Rauline, Identité(s) libertine(s). L'écriture personnelle ou la création de soi», Studi Francesi [Online], 161 (LIV | II) | 2010, online dal 30 novembre 2015, consultato il 11 janvier 2021. URL: http://journals.openedition.org/studifrancesi/6614 ; DOI: https://doi.org/10.4000/ studifrancesi.6614

Questo documento è stato generato automaticamente il 11 janvier 2021.

\section{(c)}

Studi Francesi è distribuita con Licenza Creative Commons Attribuzione - Non commerciale - Non opere derivate 4.0 Internazionale. 


\title{
Laurence Tricoche-Rauline, Identité(s) libertine(s). L'écriture personnelle ou la création de soi
}

\author{
Laura Rescia
}

\section{NOTIZIA}

LAURENCE TRICOCHE-RAULINE, Identité(s) libertine(s). L'écriture personnelle ou la création de soi, Paris, Champion, 2009, pp. 764.

1 Questo lavoro aggiunge un ulteriore tassello agli studi sulla costellazione libertina inclusi nella collezione diretta da Antony Mc Kenna per l'editore Champion. Focalizzato sulle strategie della parola libertina nelle poesie e romanzi del xVII secolo scritti in prima persona, questo volume comprende gli scritti poetici e narrativi di più generazioni, partendo da Théophile de Viau per giungere a La Fontaine, passando per Tristan l'Hermite, Charles Sorel, Cyrano de Bergerac e Charles Dassoucy.

2 Se, come noto, la pratica della scrittura soggettiva si avvale della riflessione filosofica e contribuisce a favorire l'emergenza della sfera privata nell'età moderna, gli autori libertini, per la particolare propensione alla solitudine o a tipologie di socializzazione elitarie si avvalgono particolarmente di tale prassi. La tesi dell'A. è che la finzione letteraria consenta al libertino, meglio di ogni altra forma espressiva, l'emergenza di una soggettività dissimulata e molteplice. L'io narrante dei testi che costituiscono l'oggetto di studio di questo saggio non è completamente assimilabile all'autore: non si tratta dunque di patto autobiografico in senso stretto, pur rinviando almeno in parte all'autore stesso. L'analisi di una scrittura parzialmente autobiografica consentirebbe lo studio dell'identità dissimulata attraverso le istanze del narratore e dell'eroe. Il soggetto libertino, complesso ed evanescente, ricco di ambiguità, in tal modo si confessa pur rifiutando di dar senso alla nozione di colpevolezza, e cercando la via per l'affermazione della propria autonomia. 
3 Il lavoro è suddiviso in tre sezioni. La prima è dedicata all'identità, dapprima ricercata nell'articolazione delle sfere pubblica e privata attraverso l'emersione di un'opinione pubblica libertina con la pubblicazione di testi a stampa. Il discorso prosegue alla ricerca del rinnovamento estetico, espresso nella trasformazione dei generi e nella libertà di linguaggio; e nel rinnovamento etico, realizzato nell'abbandono dell'idealismo eroico e con la riabilitazione dell'amor proprio. La seconda sezione è incentrata sulla confessione libertina, una sorta di rovesciamento burlesco che conduce alla decolpevolizzazione della dimensione corporea e delle sue funzioni. È ancora il linguaggio con le sue risorse retoriche, l'ironia in primis, a permettere l'accesso alla liberazione della corporeità individuale nelle sue diverse declinazioni: l'espressione delle passioni (lacrime e riso), i diversi "umori", i piaceri della sessualità e del desiderio, la bonne chère del nutrimento corporeo. L'esistenza libertina viene presentata come un itinerario che conduce ad una nuova consapevolezza: lungi dall'essere una conversione, tale parabola descrive l'abbandono del senso della trascendenza e l'accesso alla secolarizzazione dell'uomo moderno che, disorientato, trova una sua saggezza non nella conversione bensì nell'esercizio della prudenza e della dissimulazione. La terza sezione ci è parsa più delle precedenti orientata a mettere in luce le connessioni tra prassi letteraria e pensiero filosofico, riprendendo, approfondendo e precisando le questioni ideologiche fondamentali del variegato universo libertino: l'uso sistematico del dubbio, la valenza etica della categoria estetica della vraysemblance, il rifiuto delle superstizioni e l'orientamento anticristiano, le conseguenze politiche di tale posizione. La dimensione scettica e polemica dell'individualismo libertino non si riduce ad un antimodello, ma indica precisamente le posizioni etiche a cui si aspira per raggiungere la saggezza necessaria a vivre comme des dieux. Indipendenza, nobiltà d'animo, capacità di autosufficienza, ricerca del piacere e della soddisfazione di corpo e spirito, capacità di utilizzare le proprie risorse intellettuali e spirituali, e principalmente l'immaginazione e l'ironia, creatività espressa nella scrittura: altrettante vie per raggiungere un'idea di bonheur a portata del limite umano. Liberato dalla paura di Dio e cosciente dell'impossibilità di afferrare una qualsiasi verità, il libertino guarda alle potenzialità della sua soggettività con ironico disincanto, appena velato da un'ombra di malinconia. 